\title{
Graduates' Reflections on the Impact of International Baccalaureate Diploma Program in Tertiary Education: A Case from Turkey
}

\author{
Akın Metli* \& Halime İlarslan \\ Bilkent Erzurum Laboratory School
}

\begin{abstract}
The purpose of this study is to explore International Baccalaureate Diploma Program (IBDP) alumni's perceptions of IBDP education as well as to investigate IBDP graduates' reflections about the extent to which the IBDP education has impacted their university study at the higher education in the Turkish context. The study utilized a survey design analyzed quantitatively (descriptive statistics) and qualitatively (content analysis) to collect data from IBDP alumni ( $N=170$ out of 347) who graduated from 2012 to 2019 from a national private school implementing international education in eastern Turkey. The results of the research revealed that participants gained the IB learner profile attributes and learned how to become an internationally-minded individual through the IB education. Specifically, research participants indicated that they gained communicative skills in a foreign language, academic abilities such as researching as well as critical and analytical thinking skills, which were transferred to their post-secondary education. However, participants do not think that they are better prepared for the Turkish university entrance examination through the IBDP education they received in their secondary education. This finding is significant to show the dilemma between international education outcomes and university entrance examination preparation. Students' well-being is another possible area of investigation in the educational contexts where students are expected to comply with the requirements of both national and international education. These implications are significant for practitioners for IBDP implementation improvements at secondary schools as well as for educators for promoting recognition of international education at post-secondary institutions.
\end{abstract}

Keywords: alumni reflections, international education, International Baccalaureate Diploma Program, impact study, learner profile, post-secondary education

\section{Introduction}

The International Baccalaureate Diploma Program (IBDP) was established by the International Baccalaureate (IB) in 1968 as the first program by the IB as an international education program for students aged 16-19. The IBDP was established to provide students with a balanced education, facilitate mobility both geographically and culturally, and promote international-mindedness and the IB Learner Profile attributes such as inquirer, knowledgeable, principled, caring, balanced, risk-taker, and so forth. The mission of the IB is "to develop inquiring, knowledgeable, and caring young people who help to create a better and more peaceful world through intercultural understanding and respect. To this end, the organization works with schools, governments and international organizations to develop challenging programs of international education and rigorous assessment. These programs encourage students across the world to become active, compassionate and lifelong learners who understand that other people, with their differences, can also be right" (IB, n.d.).

The IBDP curriculum is made up of the core and six subject groups. The three core elements are Theory of Knowledge (TOK) in which students reflect on the nature of knowledge and on how we know what we claim to know; the extended essay (EE) which is an independent, self-directed research practice, and creativity, activity, service (CAS) in which students complete a project related to these three domains (IB, n.d.). The six subject groups that IBDP students study are; studies in language and literature; language acquisition, individuals and 
societies, sciences, mathematics and the arts, which consist of different courses at the standard and higher levels within each subject group. Students take three subjects at a higher level (HL) and three at standard level (SL). HL (up to 240 teaching hours) and SL (up to 150 teaching hours) courses differ in terms of scope, but are measured according to the same grade descriptors. The IB assesses student work through internal or external assessment as direct evidence of achievement against the stated goals of the DP courses (IB, n.d.).

Since there is limited research on graduates' perspectives about IBDP education in the existing literature, the purpose of this study is to explore IBDP alumni's perceptions of IBDP education they received at the high school for implications to the practitioners about the IBDP implementation improvements at schools. Many other existing studies on the impact of the IBDP education in the literature were concentrated on educational contexts in the western countries, mainly Europe and the USA, as discussed below in the literature review. Therefore, the current research study also aims to investigate IBDP graduates' reflections upon the extent to which the IBDP education has impacted their university study at higher education in the Turkish context, where international education is highly implemented both by the state and private schools. Thereby, this study is significant as it adds to the existing body of literature on the IBDP graduates' perceptions of their IBDP education as well as their reflections on the impact of IBDP education in their tertiary education.

\section{Literature Review}

There are many benefits to choosing the IBDP such as gaining breadth and depth of knowledge and developing intellectually-sophisticated individuals who are more competent in terms of knowledge, skills and dispositions at the post-secondary education compared to the non-IBDP students. Prior studies with regard to the benefits of the IBDP education identified in the existing literature revealed that enrollment in the DP significantly increased a student's likelihood of attending very good universities in the UK and most well-regarded post-secondary institutions in Mexico (HESA, 2016; Lee, 2017). Once the IBDP alumni start their tertiary education, they also show both better academic and non-academic skills at the university. IBDP has been identified as a key element for student success at the university (Culross \& Tarver, 2011) as IBDP has been found to be an important predictor of IBDP alumni's academic performance at university (Lee et al., 2017), thus is considered the best educational qualification for providing students with the necessary skills to succeed at university ("ACS", 2017).

Previous studies showed that DP graduates perform well in higher education (i.e., honors degrees or higher cumulative grade point average), add to the reputation of the universities and enroll in further education after completing university (Ateşkan et al., 2015; Büyükgenç, 2014; Caspery \& Bland, 2011; Coca et al., 2014; Conley et al., 2014; HESA, 2011; HESA, 2016; Hill \& Saxton, 2014; Inkelas et al., 2013; Lee et al., 2017). Furthermore, according to the results of various studies (Aldana, Mayer \& Ee, 2020; Ateşkan et al., 2015; Bergeron, 2015; Conley et al., 2014; Halic, 2013; Pilchen, Caspary, \& Woodworth, 2020), IBDP students enroll, persist, and graduate on time at notably higher rates compared to the non-IBDP students.

Furthermore, prior research also suggests that IBDP participation improves secondary school academic performance (Caspary, 2011; Saavedra, 2011; Wade, 2011) and also beyond at postsecondary education. Researchers investigated graduates' perspectives with regard to the impact of the IBDP on college preparedness and found that IB graduates reported a higher sense of college preparedness (Saavedra, Lavore \& Flores, 2013; Smith, 2009). Higher education preparedness was particularly evident in academic skills, such as higher-order thinking skills such as critical-analytical thinking, research skills, and managing independent work (Ateşkan et al., 2015; Demir, 2009; Wright, 2015), preparation for the challenge of college coursework including study skills, research skills, time management (Aldana, Mayer \& Ee, 2020; Conley et al., 2014).

The impact of the IBDP in terms of preparedness for postsecondary education was also evident in the nonacademic areas (Coca et al., 2012), as well, particularly with regard to creativity, leadership, oral expression skills, international-mindedness, lifelong learning, and open-mindedness (Aulls \& Peláez, 2013; Culross \& 
Tarver, 2011; Demir, 2009; Lee et al., 2017; Taylor \& Porath, 2006). Other than academic and non-academic benefits at postsecondary education, IBDP alumni also reported that participation in the IBDP would be an advantage for their prospective occupational careers (Büyükgenç, 2014).

As for graduates' perspectives about the IBDP education at the secondary school, previous studies revealed both positive and negative student experiences. Positive perceptions regarding the IBDP education were related to higher academic achievement and academic persistence compared to non-IBDP students (Holman et al., 2016), pedagogy offered in the IBDP (i.e., well-organized, engaging and student-centered classroom environment (Barnett, 2013); skills-based nature of the IBDP education for promoting $21^{\text {st }}$ century skills to develop globalmindedness, leadership skills and critical thinking (Büyükgenç, 2014; Cole et al., 2014; Demir, 2009; Lee et al., 2017), as well as students' pride and self-confidence for coping with challenging work (Foust, Hertberg-Davis, \& Callahan, 2009).

However, negative perceptions were related to the greater level of academic challenge (i.e., too much homework) and the socially limiting heavy workloads which can result in time management problems, high levels of stress, fatigue, and anxiety among students (Büyükgenç, 2014; Foust, Hertberg-Davis, \& Callahan, 2009; Hertberg-Davis \& Callahan, 2008). IBDP alumni's perceptions about the components of the IBDP education specifically focused on the core components of the IBDP such as Theory of Knowledge (TOK); Creativity, Activity and Service (CAS); Extended Essay (EE) which were highlighted as providing opportunities to develop communication, creativity, critical thinking, research skills, global-mindedness, cultural sensitivity, and leadership skills and interpersonal skills (Conley et al., 2014; Hayden et al., 2017; Lee et al., 2017, Metli, 2018; Saavedra, Lavore \& Flores, 2013).

Based on this literature review, one can note that most of the earlier studies focused on the IBDP graduates' academic achievement levels, retention or graduation rates and student experiences during the IBDP education. This current study is significant because it explores the IBDP alumni's perceptions of the IBDP education they received at the high school and also the impact of the IBDP education at the university at the same time. Besides, since earlier studies were only conducted in the USA, Europe and Far East countries, it is important to investigate the phenomenon in the Middle-East context, as well. As such, this study yields important implications about the alignment gaps between the university entrance examination and the IBDP assessment in the Turkish context. Furthermore, most studies in the literature are more focused on the impact of the IBDP at the university rather than students' reflections and experiences during their IBDP education. Thereby, with the help of a larger sample size, this study presents original, novel and authentic student reflections on their expectations, challenges, or strategies with regard to the IBDP education in their secondary education.

\section{Methods}

This research utilized a survey design to investigate the phenomenon under investigation. The questions of the survey were mainly based on a prior study by Taylor and Porath (2006) conducted on IBDP graduates' perspectives about the IBDP. This online survey of IBDP graduates from a private high school was administered remotely in spring 2020. This school, located in eastern Turkey, was founded in 2007 as a private school that implements both the national curriculum and international curricula (IGCSE and IBDP) as part of the graduation requirements. This is the only high school that provides mandatory IB education to Turkish students on scholarships in eastern Turkey.

Graduates from 2012 (first graduating class) to 2019 (the most recent graduating class) were selected as the research participants of the current study to have a bigger sample compared to the existing studies on the IBDP graduates' perspectives and reflections with limited sample (Büyükgenç, 2014; Demir, 2009; Taylor and Porath, 2006). All IBDP alumni who graduated from the case school were initially contacted through email as well as phone for invitation to the research. The ethical approval was taken from the case school's administration and 
directorate of education to undertake this research. Consents were taken online from the research participants who were all above 18 years old. Out of 347 graduates in total, 170 graduates (83 male and 87 female students) accepted to participate in the research. The data were collected through the online Google form survey which was completed by the participants in early May 2020.

The survey included three parts, which were all mandatory to complete (only except for any other comments section on Part 3). The first part included demographic questions such as their gender, graduation year of the IBDP, the university they study, department enrolled at the university, and the year of registration at the university (i.e., freshman, sophomore, junior, senior, $\mathrm{MA}$ or $\mathrm{PhD}$ graduate degree, etc.) The second part of the survey was a closed-ended section. This part included twenty statements for which the research participants were asked to respond using the 4 point Likert-type scale, with $1=$ strongly agree, $2=$ agree, $3=$ disagree, and $4=$ strongly disagree. The third part of the survey was an open-ended section. This part included questions for which the research participants were asked to respond with their comments to the questions provided. The statements from Part 2 (closed-ended) and the questions (open-ended) from Part 3 of the survey administered are provided in Appendix. The closed-ended statements and open-ended questions were complementary to one another in terms of content and provided triangulation of the data for the reliability of the research. Both sections were also complementary for data collection and analysis because researchers desired to collect not only numeric data on students' levels of agreements/disagreement on the perceptions as well as the impact of the IBDP program, but also qualitative data about their perspectives on the IBDP and patterns behind their levels of agreement/disagreement.

The closed-ended part of the survey was analyzed quantitatively with descriptive statistics in the Google form in terms of the percentages of answers for each item. The open-ended part of the survey was analyzed through thematic content analysis in which the researcher looked for common themes and differences across research participants. Keywords were coded and patterns that emerged were noted in Nvivo11 Pro. It was used to organize, re-code, and re-analyze data as emerging thematic codes were developed and reported in the results section.

\section{Results}

\section{Part 1: Demographic Information}

170 graduates ( 83 male and 87 female alumni) of the IBDP education from the case school participated in this research. 170 graduates completed each part of the online survey as each item in each part of the survey was mandatory to complete for the research participants. The number of participants and its percentages of the graduation years of the case school is shown in Table 1 .

Table 1. Participants' Graduation Years from the Case School

\begin{tabular}{lll}
\hline Graduation Year & Participation Percentage & $\begin{array}{l}\text { Number of } \\
\text { Participants }\end{array}$ \\
\hline 2012 & $11.8 \%$ & 20 \\
\hline 2013 & $16.5 \%$ & 28 \\
\hline 2014 & $8.2 \%$ & 14 \\
\hline 2015 & $13.5 \%$ & 23 \\
\hline 2016 & $14.1 \%$ & 24 \\
\hline 2017 & $8.2 \%$ & 14 \\
\hline 2018 & $10.6 \%$ & 18 \\
\hline 2019 & $19.1 \%$ & 29 \\
\hline
\end{tabular}


Almost all participants indicated that they study or have studied at foundation/private universities (mostly in the capital city, Ankara) in Turkey. The research participants indicated that they study at the departments of law, medicine, dentistry, business management, economics, international relations, political science and public administration, architecture, interior architecture and environmental design, psychology, electrics-electronics engineering, industrial engineering, computer engineering, mechanical engineering. Table 2 shows the university level of the research participants below.

Table 2. The University Level of the Research Participants

\begin{tabular}{lll}
\hline University Level & Participation Percentage & Number of Participants \\
\hline $\begin{array}{l}\text { Preparatory year } \\
\text { English language program) }\end{array}$ & None & None \\
\hline Freshman (first year) & $18.8 \%$ & 32 \\
\hline Sophomore (second year) & $8.2 \%$ & 14 \\
\hline Junior (third year) & $8.8 \%$ & 15 \\
\hline Senior (fourth year) & $17.1 \%$ & 29 \\
\hline MA (Master of Arts) & $8.2 \%$ & 14 \\
\hline PhD (Doctor of Philosophy) & $1.2 \%$ & 2 \\
\hline Graduated from the university & $37.6 \%$ & 64 \\
\hline
\end{tabular}

\section{Part 2: Results about the closed-ended statements}

The percentages of the level of agreement/disagreement presented on the Likert scale are presented in Table 3 .

Table 3. Percentages of Likert Responses on Survey Part 2

\begin{tabular}{|c|c|c|c|c|}
\hline \multirow[b]{2}{*}{ Survey Part 2} & \multicolumn{4}{|c|}{ Participants' responses } \\
\hline & $\begin{array}{l}\text { Strongly } \\
\text { disagree }\end{array}$ & Disagree & Agree & $\begin{array}{l}\text { Strongly } \\
\text { agree }\end{array}$ \\
\hline Statement 1 & $\% 1.2$ & $\% 1.8$ & $\% 17.1$ & $\% 80$ \\
\hline Statement 2 & $\% 0.6$ & $\% 3.5$ & $\% 20$ & $\% 75.9$ \\
\hline Statement 3 & 0 & $\% 1.8$ & $\% 21.8$ & $\% 76.5$ \\
\hline Statement 4 & 0 & $\% 3.5$ & $\% 18.8$ & $\% 77.6$ \\
\hline Statement 5 & $\% 2.4$ & $\% 10$ & $\% 40$ & $\% 47.6$ \\
\hline Statement 6 & $\% 12.4$ & $\% 26.5$ & $\% 39.4$ & $\% 21.8$ \\
\hline Statement 7 & $\% 10.6$ & $\% 32.4$ & $\% 36.5$ & $\% 20.6$ \\
\hline Statement 8 & $\% 5.3$ & $\% 21.2$ & $\% 34.1$ & $\% 39.4$ \\
\hline Statement 9 & 0 & $\% 1.2$ & $\% 13.5$ & $\% 85.3$ \\
\hline Statement 10 & 0 & $\% 0.6$ & $\% 19.4$ & $\% 80$ \\
\hline Statement 11 & $\% 0.6$ & $\% 5.3$ & $\% 18.2$ & $\% 75.9$ \\
\hline Statement 12 & $\% 2.9$ & $\% 6.5$ & $\% 25.3$ & $\% 65.3$ \\
\hline Statement 13 & 0 & $\% 1.2$ & $\% 17.1$ & $\% 81.8$ \\
\hline Statement 14 & $\% 34.1$ & $\% 35.9$ & $\% 21.8$ & $\% 8.2$ \\
\hline
\end{tabular}




\begin{tabular}{lllll}
\hline Statement 15 & $\% 3.5$ & $\% 9.4$ & $\% 31.2$ & $\% 55.9$ \\
\hline Statement 16 & $\% 1.8$ & $\% 9.4$ & $\% 25.9$ & $\% 62.9$ \\
\hline Statement 17 & $\% 0.6$ & $\% 7.6$ & $\% 25.3$ & $\% 66.5$ \\
\hline Statement 18 & $\% 1.2$ & $\% 5.9$ & $\% 27.6$ & $\% 65.3$ \\
\hline Statement 19 & 0 & $\% 4.1$ & $\% 5.9$ & $\% 90$ \\
\hline Statement 20 & $\% 2.4$ & $\% 6.5$ & $\% 24.1$ & $\% 67.1$ \\
\hline
\end{tabular}

\section{Part 3: Results about the open-ended questions}

\section{Reasons for participation in the IBDP}

Most of the students stated that they chose the IBDP to have quality international education and gain a bilingual internationally-recognized diploma. Specifically, most students stated that the IBDP gives students to develop their academic abilities such as critical and creative thinking skills, problem-solving skills, global awareness, intercultural understanding, and foreign language speaking skills. Some students also added that the IBDP was better than the regular (national) program in terms of academic and social support and the variety of course offerings. Few students pointed out that they would use the IBDP diploma to be awarded with the academic merit scholarships at the universities or they were required to study the IBDP at the case study school.

\section{Expectations about the IBDP}

The majority of the students indicated that the participation in IBDP met their expectations. Most stated that participation in the IBDP met their expectations because they aimed to be better prepared for the academic expectations of the university beyond memorization skills (e.g. research skills, critical thinking), communicate effectively (both written and oral in their native and foreign languages), and get engaged in social activities (e.g. community service, sports, drama, music). Some students stated that the IBDP partially met their expectations because they could not spare time for practicing for the university entrance examination, which is just a multiple-choice test. Others stated that the scope of topics covered in the IBDP and the national program were different which challenged them in terms of their preparation for the university or the challenging and demanding IBDP limited their social life. Several students referred to the international universities they applied with the help of this internationally-recognized diploma they received. A few of them stated that the graduation requirement impacted their motivation in their academic study, as illustrated by one of the participants: "Concerns on getting the diploma for graduation mostly overshadows the eager to learn and the curiosity to explore."

\section{Personal Gains in the IBDP}

Most participants stated that participation in the IBDP helped them improve their self-discipline (time management, stress resistance, perseverance, self-confidence, self-motivation), develop their international mindedness (global awareness, open-mindedness, and intercultural competence), advance thinking skills (reflective, inquiry, analytical and critical thinking), and foreign language communications skills (both in English and German). Some students also pointed out that they developed their research skills, learned how to deal with challenges, get engaged in entrepreneurship, and be better prepared for the academic expectations of post-secondary education. 


\section{Beneficial aspects of participation in the IBDP}

Many participants referred to the IB's learner profile as they reflected on the most beneficial aspects of participating in the IBDP. Profile. Specifically, these participants referred to the key attributes of the learner profile such as knowledgeable, principled, open-minded, caring, inquirer, and reflective. Others focused on the various abilities they gained through their participation in the IBDP as illustrated by one of the participants: "IBDP gives you the chance of developing yourself in a variety of fields including academic, artistic, and social activities." Participants specifically referred to both personal and academic abilities they gained such as time management, team-work, researching, analytical and creative thinking, and writing skills. Several students referred to the benefits of the IBDP in terms of their post-secondary education, as illustrated by one of the participants: "Participating in the IB made my university life much easier in terms of both my curricular and extracurricular activities...and adapting to the university courses." Few participants referred to life-long learning as well as intercultural competence or international-mindedness.

\section{Challenges faced while studying the IBDP}

The majority of the students stated that the high workload (e.g. assignments, summer school, mock exams, etc.), numerous internal and external requirements and preparation for both the national program and international program simultaneously were the main challenges they encountered. As one participant pointed out, "This program had lots of requirements causing serious anxiety. The requirements for each course were heavy, to complete all the requirements perfectly. I had so limited time for studying for Turkish Curriculum, and it was so stressful to handle my IB papers and University entrance examinations together at the same time." Other students also pointed out that the core components (Extended Essay, Theory of Knowledge, Creativity, Activity and Service) were intensive, rules about deadlines were strict, managing time and stress was difficult, the scope and assessment model of the national and international programs were too different, independent learning and researching was unfamiliar, and lastly, the content of the high-level courses was so challenging. There were also some others who noted some negative comments regarding the lack of support from their school in terms of motivation or constructive feedback on their progress, inexperienced teachers who were not quite knowledgeable about the international program requirements (as well as constantly changing teachers at their school), and the pressure from the school administration about academic excellence. A few of them focused more on their weaknesses in their foreign language (English) communication skills (especially in oral presentations), graduation requirement of their school, and the adaptation to an educational international program. Only a couple of participants stated that they did not face any challenges at all during their IBDP study.

\section{Strategies used to handle the obstacles during the study of the IBDP}

Most participants stated that they handled the obstacles they encountered during their study in the IBDP through employing better strategies for their study habits, practicing for the external examinations through the past papers, using external sources such as online video lectures, and trying to keep their motivation high. Some other participants stated that they consulted their teachers, counselors, family members, classmates (or seniors) for academic support, managed their time more effectively through using an online calendar and reminder software) and tried to keep their motivation high by both controlling their level of stress and thinking about the benefits of the IBDP education and university life. Few students pointed out that they just spent time with their hobbies and created free time for themselves for dealing with the demands and challenges of the international program. 


\section{The impact of the IBDP at the university study}

Most participants indicated that participation in the IBDP impacted their study at the university positively because they learned necessary study habits such as time management, developed academic abilities such as researching, improved their communication skills such as making presentations, and developed their personal skills such as building self-confidence or managing their stress and finally helped them socially by engaging in extracurricular activities. Some other participants made some remarks such as "studying at university is easier than IBDP" or "after the IBDP, the university becomes very boring and meaningless" or "university education does not challenge me as IBDP". There were also few participants who were critical of the IBDP education as they stated that the standard level of the IBDP courses was not helpful for the university courses.

\section{Skills transferred from the IBDP to your university study}

Many participants indicated that they were able to transfer skills from the IBDP to their university study. They stated that they transferred skills such as critical thinking, problem-solving, intercultural understanding, and analytical inquiry, working collaboratively, and communicating fluently and clearly. Some referred to the IB's Learner Profile, specifically the attributes of inquirer, risk-taker, balanced, and communicator. Few students referred to academic integrity, learning to learn, multi-tasking and personal goal-setting.

\section{The influence of the specific components of the IBDP on the university study}

The majority of the participants referred to the key components (Creativity, Activity and Service, Theory of Knowledge, and Extended Essay) of the IBDP which they considered as a major impact on their study at the university. For Theory of Knowledge, they stated that it helped them develop their higher-order thinking skills (e.g. analysis, synthesis and evaluation) as well as intercultural sensitiveness about global issues or cultural perspectives. Some other participants indicated that TOK helped them look at issues from multiple perspectives and present their points of view clearly, especially in their humanities courses. For Extended Essay, participants stated that it helped them how to do research, build an argument, and write clearly for an academic paper. For Creativity, Activity and Service, participants stated that it helped them develop their social skills, especially communication skills or self-confidence. They also stated that it helped them become a more mature individual through a more caring and sensitive attitude toward life. Some other students referred to the other aspects of the IBDP as an impact on their university life. They stated that their high-level courses, individual oral commentaries, internal assessments and assignments, lab experiments and individual oral presentations helped them greatly in their academic preparedness at the university. However, these participants did not specifically explain how these components of the IBDP helped them in their university life.

\section{General comments on the IBDP}

For this general comment section, many participants stated that they were grateful to the opportunity to get this program. They thanked their teachers and school administration for proving them with a quality educational program. There were also some positive remarks from the participants concerning the international education they received at their school such as: "IBDP is certainly a preparation time not only for the university but also for life. When I take a job interview, they ask me about my high school, not my university". "IB is a very success-oriented curriculum that teaches the student social and practical skills as well as academic skills. I always recommend to the ones around me to have their children study IBDP". "It looks hard when studying, but the advantages are realized later in the university. I still help my family members with their academic stuff. I can talk or make comments about biology, computer science, literature and history freely and confidently." Some other participants pointed out that the books read made them very intellectual, or the English Literature and Performance class they participated in helped them greatly for their foreign language speaking skills. A couple of students made suggestions regarding how their school should support students for the assessment of 
international examination and university entrance examination simultaneously or whether the students can study the IBDP in the 10th and 11th grade so that they could prepare for the university entrance examination and cope with the stress of the university entrance examination.

\section{Discussion}

This research aimed to explore IBDP alumni's perceptions of IBDP education as well as to investigate IBDP graduates' reflections upon the extent to which the IBDP education has impacted their university study. Both the open-ended and closed-ended parts of the online survey findings consistently revealed that the IBDP education provided an intellectually-stimulating learning environment where graduates have gained the IB learner profile attributes and learned how to become an internationally-minded individual who is multilingual, interculturallycompetent, and globally-engaged.

Furthermore, many research participants indicated that they chose to study this international educational program because they wanted to improve their foreign language, study abroad, or get prepared for their tertiary education through an enriched and balanced international program. Their reflection showed that after completing the IBDP, they gained better communicative skills in both their native tongue and in their foreign language (English), academic abilities such as researching as well as critical and analytical thinking skills, which were believed to be transferred to their post-secondary education at the university. These findings of the current study also matched with the existing findings on the benefits of the IBDP education in the literature (Aldana, Mayer \& Ee, 2020, Ateşkan et al., 2015; Aulls \& Peláez, 2013; Conley et al., 2014; Culross \& Tarver, 2011; Demir, 2009; Lee et al., 2017; Taylor \& Porath, 2006; Wright, 2015).

As for the challenges participants encountered during their study in IBDP, most of the participants agreed that the content of the IBDP courses was intense and challenging; thus, they encountered personal challenges such as stress, reluctance, time management, tiredness during their focused study on both the IBDP and the national curriculum. These challenges were also previously identified and discussed in the previous research (Büyükgenç, 2014; Feld \& Shusterman, 2015; Foust, Hertberg-Davis, \& Callahan, 2008; Ganzeboom, 2017; Hearon, 2015; Nagel, 2017; Suldo \& Shaunessy-Dedrick, 2013)

Although participants of the current study did not believe that the IBDP helped them get prepared for the university entrance examination, they believe that compared to the non-IB graduates, they were still better prepared for their university courses with the help of the IBDP education, especially with the help of the highlevel courses as well as the core components of the IBDP, such as TOK, CAS and EE, as already indicated in previous research (Hayden et al. 2017; Metli \& Martin, 2018), too. Overall, almost all of the participants were pleased with the IBDP education they received from their secondary school and the benefits that the IBDP education presented.

Despite the benefits of the IBDP education for students' postsecondary education in terms of their academic achievement and transferred academic abilities at the university or the perceived challenges they have encountered during their IBDP study match with the findings from the prior research in the literature, the current study revealed that Turkish students do not think that they are better prepared for the Turkish university entrance examination through the IBDP education they received in their secondary education. One of the reasons why they may think so is because the Turkish university entrance examination (delivered as a multiple-choice test on language, literature, science, math and social studies in Turkish every year for around 2 million candidates) and the IBDP external examination (delivered as mainly short answer or essay type in English) are quite different in terms of required assessment objectives and skills. This is also consistent with the findings of the study by Metli and Özcan (2020) who examined to what extent IBDP success is a predictor of students' rank orders in the university entrance exam as well as whether there is any correlation in terms of students' academic achievement in the IBDP exam and university entrance exam. Metli and Özcan's (2020) study showed no strong relationship 
between the academic performance of alumni in IBDP exams and the Turkish university entrance exam. Another study conducted in the Turkish context by Sagun (2016) also emphasized that although non-IBDP students show better academic performance in the Turkish university entrance exam compared to their IBDP peers, IBDP students show better academic performance (e.g. higher GPA or higher rate of retention) during their university study. Both of the quantitative studies by Sagun (2016) and Metli and Özcan (2020) support the qualitative findings of this research in terms of the IBDP alumni's perspectives, perceptions and reflections on the IBDP program and its impact on their university study.

\section{Conclusion}

The current research showed that IBDP alumni from this case school had very positive perceptions about this international education and its impact on their post-secondary education. Compared to their peers who only study the national curriculum, the research participants think they are academically, socially, emotionally and cognitively better prepared for their life at the university through their study in both the national and international curriculum. Many participants referred to the key skills of the 21 st century such as self-confidence, communicative skills, intercultural sensitivity, social responsibility, interdisciplinary and team-work skills that they will use not only at the university but at the workplace and beyond.

This study raises some important implications for schools to improve their practices of the implementation of the IBDP through the reflections of the IBDP alumni based on these findings from this research. School leaders and teachers can use the findings of the current study to promote the IBDP as an international program. Furthermore, various stakeholders such as boards of schools, heads of schools or other administrators can use these findings for their decision-making on the authorization or evaluation process of the international program implementation at their schools. Besides, the findings of the current study add to the existing body of literature about the benefits of the IBDP education for the university study, thus these findings can be referred for the recognition of the IBDP at universities (both state and foundation) in Turkey.

The study has some limitations that need to be taken into consideration. First of all, the study only concentrated on one case school from which all the research participants graduated. Secondly, in order to increase the number of research participants, authors invited graduates who graduated from 2012 to 2019; however, going back so far may have made it difficult for the research participants to recall in clarity about their reflections on the IBDP and its impact on their university study. Lastly, the research was limited in terms of its methodology to collect data as the survey was only the main data collection tool, so further future studies may include some other qualitative instruments such as interviews and focus groups.

This current study suggests further research into the investigation of the IBDP as an international education program. The authors recommend that other than exploring the alumni's reflections on the impact of the IBDP on postsecondary education, firstly, researchers can also explore the reflections of the IBDP graduates on the impact of the IBDP as an international program on their profession and workplace. Secondly, researchers can conduct similar research on other international programs such as Advanced Placement (AP) or International General Certificate of Secondary Education (IGCSE) to explore the extent to which these international programs help students prepare for postsecondary education. Thirdly, researchers can conduct further research to investigate the perceptions of the university professors on the IBDP alumni and their academic performance in their courses at the university. Fourthly, the IB can further investigate IBDP students' well-being in the program and find strategies to help the students about workload and time management, and stress on the external examinations. Especially, further research is recommended on the well-being of students who are expected to comply with the requirements of both national and international education. Finally, researchers can specifically focus on the IBDP learner profile as the key aspect of the mission of the IB education and explore to what extent IBDP alumni believe they have reached the mission of the IB education. 


\section{Declaration of Interest}

The authors declare that there is no conflict of interest.

\section{References}

ACS International Schools. (2017). Thriving at university: University admissions officers report 2017. Retrieved from https://www.acsschools.com/university-admissions-officers-report-2017.

Aldana, U., Mayer, A., \& Ee, J. (2020). The impact of the IB Diploma Programme in public schools in the United States serving students from low-income households. Bethesda, MD, USA: International Baccalaureate Organization.

Ateşkan, A., Onur, J., Sagun, S., Sands, M., \& Çorlu, M.S. (2015). Alignment between the DP and MoNEP in Turkey and the effects of these programmes on the achievement and development of university students. Bethesda, MD, USA: International Baccalaureate Organization.

Aulls, M.W., \& Peláez, S. (2013). Exploring the learning benefits and outcomes of the IB extended essay in preparing students for university studies in Canada: Student perceptions of the impact of the Diploma Programme and the extended essay on the academic demands of first year in university. Montreal: Department of Educational and Counselling Psychology, McGill University.

Barnett, E. (2013). Implementation of the Diploma Programme in Ecuador's state schools. Bethesda, MD, USA: International Baccalaureate Organization.

Bergeron, L. (2015). Diploma Programme students' enrollment and outcomes at US postsecondary institutions 2008-2014. Bethesda, MD, USA: International Baccalaureate Organization.

Büyükgenç, F. (2014). Reflections on the International Baccalaureate Programme: Graduates' perspectives. (Unpublished master's thesis). Ankara University, Turkey.

Caspary, K. (2011). Postsecondary enrollment patterns of IB certificate and diploma candidates from international high schools. Research Brief. Menlo Park, CA, USA: SRI International.

Caspary, K., \& Bland, J. (2011). First college courses taken by Florida IB students. Research Brief. Menlo Park, CA, USA: SRI International.

Coca, V., Johnson, D., Kelley-Kemple, T., Roderick, M., Moeller, E., Williams, N., \& Moragne, K. (2012). Working to my potential: The postsecondary experiences of CPS students in the International Baccalaureate Diploma Programme. Chicago, IL: The University of Chicago Consortium on Chicago Schools Research.

Cole, D. R., Gannon, S., Ullman, J., \& Rooney, P. (2014). Theory of knowledge (TOK): Exploring learning outcomes, benefits and perceptions. Bethesda, MD, USA: International Baccalaureate Organization.

Conley, D., McGaughy, C., Davis-Molin, W., Farkas, R., \& Fukuda, E. (2014). International Baccalaureate Diploma Programme: Examining college readiness. Bethesda, MD, USA: International Baccalaureate Organization.

Culross, R., \& Tarver, E. (2011). A Summary of research on the International Baccalaureate Diploma Programme: Perspectives of students, teachers, and university admissions offices in the USA. Journal of Research in International Education, 10(3), 231-243.

Demir, N. K. (2009). The points of the principals, teachers, parents and graduates related to International Baccalaureate Diploma Programme. (Unpublished doctoral thesis). Ankara University, Turkey.

Feld, L. D., \& Shusterman, A. (2015). Into the pressure cooker: Student stress in college preparatory high schools. Journal of Adolescence, 41, 31-42.

Foust, R. C., Hertberg-Davis, H., \& Callahan, C. (2009). Students' perceptions of the non-academic advantages and disadvantages of participation in Advanced Placement courses and International Baccalaureate programs. Adolescence, 44(174), 289-312. 
Ganzeboom, H. (2017). Student workload and well-being during the International Baccalaureate Diploma Programme: A three-wave panel study. Presented at American Educational Research Association Annual Meeting, San Antonio, United States.

Halic, O. (2013). Postsecondary educational attainment of IB Diploma Programme candidates from US high schools. Bethesda, MD, USA: International Baccalaureate Organization.

Hayden, M., Hemmens, A., McIntosh, S., Sandoval-Hernández, A., \& Thompson, J. (2017). The impact of creativity, action, service (CAS) on students and communities. Bethesda, MD, USA: International Baccalaureate Organization.

Hearon, B. V. (2015). Stress and coping in high school students in accelerated academic curricula: Developmental trends and relationships with student success (Unpublished doctoral dissertation). University of South Florida.

Hertberg-Davis, H., \& Callahan, C. M. (2008). A narrow escape: Gifted students' perceptions of advanced placement and International Baccalaureate Programs. Gifted Child Quarterly, 52(3), 199-216.

Higher Education Statistics Agency (HESA). (2016). International Baccalaureate students studying at UK higher education institutions: How do they perform in comparison with A level students? Bethesda, MD, USA: International Baccalaureate Organization.

Higher Education Statistics Agency (HESA). (2011). International Baccalaureate students studying at UK Higher Education Institutions: How do they fare? UK: HESA.

Hill, I. \& Saxton, S. (2014). The International Baccalaureate (IB) Programme: An international gateway to higher education and beyond. Higher Learning Research Communications, 4(3), 42-52.

Holman, A., Pascal, E.A., Bostan, C., Hoşbotă, A.M., and Constantin, T. (2016). Developing academic persistence in the International Baccalaureate Diploma Programme: Educational strategies and associated personality traits. Bethesda, MD, USA: International Baccalaureate Organization.

IB. (n.d). Diploma Programme. Retrieved from https://www.ibo.org/programmes/diploma-programme/

Inkelas, K. K., Swan, A., Pretlow, J., \& Jones, J. (2013). Exploring the Benefits of the International Baccalaureate extended essay for university study at the University of Virginia. Charlottesville, VA, USA: Center for Advanced Study of Teaching and Learning in Higher Education, University of Virginia.

Lee, M., Spinks, J. A., Wright, E., Dean, J., \& Ryoo, J. H. (2017). A study of the post-secondary outcomes of IB Diploma alumni in leading universities in Asia Pacific: Report for the International Baccalaureate Organization. Bethesda, MD, USA: International Baccalaureate Organization.

Metli, A., \& Martin, R. A. (2018). The development of international-mindedness: An investigation into how IBDP core components (TOK, CAS, and EE) foster students' multilingualism, intercultural understanding and global engagement. Bethesda, MD, USA: International Baccalaureate Organization.

Metli, A., \& Özcan, O. (2020). Relationship between achievement performances of university entrance examination and International Baccalaureate Diploma Program: A case from Turkey, Manuscript submitted for publication.

Nagel, I. (2017). Workload in the International Baccalaureate Diploma Programme: Objective situation versus subjective report. Presented at American Educational Research Association Annual Meeting, San Antonio, United States.

Pilchen, A., Caspary, K., \& Woodworth, K. (2020). Postsecondary outcomes of International Baccalaureate Diploma Programme graduates in the United States. Bethesda, MD, USA: International Baccalaureate Organization.

Saavedra, A. (2011). The academic impact of enrollment in International Baccalaureate Diploma Programs: A case study of Chicago public schools. Santa Monica, CA, USA: RAND Corporation. Retrieved from http://www.rand.org/pubs/ working_papers/WR867.

Saavedra, A. R., Lavore, E., \& Flores, G. (2013). The International Baccalaureate Diploma Programme in Mexico as preparation for higher education. Bethesda, MD, USA: International Baccalaureate Organization. 
Sagun, S. (2016). Students' performance, skills and perspectives on the combination of national and international curricula for university education in Turkey. (Unpublished doctoral dissertation). Bilkent University, Turkey.

Smith, S. S. (2009). The Advanced Placement and International Baccalaureate Programs: The graduates' perspective. (Unpublished doctoral thesis). The University of Southern Mississippi, USA.

Suldo, S. M., \& Shaunessy-Dedrick, E. (2013). Changes in stress and psychological adjustments during the transition to high school among freshmen in an accelerated curriculum. Journal of Advanced Academics, 24(3), 195-218.

Taylor, M., \& Porath, M. (2006). Reflections on the International Baccalaureate Programme: Graduates' perspectives. The Journal of Secondary Gifted Education. 17(3), 149-158.

Wade, J. (2011). Student performance and student engagement in the International Baccalaureate Middle Years Programme. Bethesda, MD, USA: International Baccalaureate Organization.

Wright, K. (2015). International Baccalaureate Programmes: Longer-term outcomes. Bethesda, MD, USA: International Baccalaureate Organization.

\section{Appendix}

\section{Survey: Part 2 - Closed-ended part}

1) Compared to the regular (national) program, I had the opportunity to study more varied academic courses in IBDP education.

2) Having participated in IBDP helped me attend more extra and co-curricular activities compared to the regular (national) program.

3) IBDP education provided an intellectually-stimulating learning environment where I have gained the IB learner profile attributes.

4) IBDP education taught me how to become an internationally-minded individual.

5) The content of the IBDP courses was challenging.

6) The IBDP assessment was so rigorous and challenging that I felt stressed about achieving the program.

7) The IBDP workload was intense but it did not influence my well-being in a negative way.

8) I have encountered many personal challenges (such as stress, reluctance, time management, tiredness, etc.) during my participation in the IBDP study.

9) The IBDP courses helped me gain critical and analytical thinking skills.

10) The IBDP courses helped me gain reflective thinking skills.

11) IBDP education helped me gain life-long learning skills.

12) IBDP education helped me become more aware of global issues and problems.

13) IBDP education helped me develop my communication skills both in my native tongue and in a foreign language.

14) IBDP education helped me show a better performance in the university entrance exam. 
15) Compared to my peers who are non-IB graduates at the university, I am better prepared for my BA (Bachelor of Arts) program.

16) Since I participated in the IBDP, I have been better prepared for the requirements of my university courses.

17) Studying IBDP at high school helped me meet the expectations of my university.

18) IBDP education helped me transfer academic and social skills from the IBDP to the university study.

19) I do not regret that I have completed my IBDP education at high school.

20) Overall, I have been pleased with the IBDP education I have received at my high school.

\section{Survey: Part 3 - Open-ended part}

1) Why did you choose to participate in the IBDP?

2) Did the participation in the IBDP meet your expectations? Please explain.

3) What did you personally gain through your participation in the IBDP?

4) What were the most beneficial aspects of participating in the IBDP? Why? Please explain.

5) What were the challenges you faced during your study in the IBDP?

6) How did you handle the obstacles you encountered during your study in the IBDP?

7) How did participation in the IBDP impact your study at the university?

8) Are there any skills that you have transferred from the IBDP to your university study? Please explain.

9) Which aspects of the IBDP influenced your study at the university? Please explain.

10) Any other comments? 